MEDICAL X-RAY TECHNIQUE 


\title{
MEDICAL X-RAY TECHNIQUE
}

\author{
Prof. Dr. G. J. VAN DER PLAATS
}

Former Chief Radiologist St. Annadal Hospital, Maastricht

Third revised and enlarged edition 
This book contains XIV +587 pages, 222 illustrations and 16 plates U.D.C. nr. 615.849:616-073.75

(C) Centrex Publishing Company, Eindhoven, The Netherlands, 1969

All rights reserved

Softcover reprint of the hardcover 3rd edition 1969

\author{
ISBN 978-1-349-00063-0 ISBN 978-1-349-00061-6 (eBook) \\ DOI 10.1007/978-1-349-00061-6
}

First edition 1959

Second enlarged edition 1961

Third revised and enlarged edition 1969

No representation or warranty is given that the matter treated in this book is free from patent rights: nothing herein should be interpreted as granting, by implication or otherwise, a licence under any patent rights 


\section{PREFACE}

The days have gone for ever when hospital nurses and others trained themselves as X-ray assistants by process of trial and error. With the increasing use of various types of radiation, which present much greater hazards to the operating personnel, and the increasing demands for greater technical experience in radiological procedures, it has become necessary to hold courses for the training of radiographers.

It was with such courses in mind that, when approached to write a text-book on Medical X-ray Technique, I gladly accepted.

It was decided to base the book on not too low a level and to assume a certain knowledge of mathematics and physics, so that the treatment of basic elementary ideas could be omitted.

In view of the number of well written and copiously illustrated books on radiographic positioning and centering, these subjects were intentionally passed over. The few radiographs which are included in this book serve only as examples of the techniques indicated in the text; there is and can be no question of a complete range of representative radiographs.

Though it does not directly come under the title of this work, I considered it imperative to include a chapter on radioactive isotopes, in view of the close relationship which exists between this subject and the radiological problems treated in the therapy section.

Certain points have been treated with extra thoroughness in order to ensure that the radiographer is in full possession of the knowledge necessary to carry out all types of procedures, which call for highly specialized experience. Such detailed information appears throughout the book in small print. In some instances the large print deals with the same subject matter as the smaller print; in the latter the treatment is either more thorough or more elaborate.

In some places, where matters of importance are concerned, I have not hesitated to resort to repetition. For the sake of greater clarity, diagrams rather than photographs have been chosen as illustrations. Many of the diagrams have been taken in whole or in part from existing works by Eggert, Schinz, Raver, Lamarque, Kepp, Barth, Wachsmann and Lenihan, to whom due acknowledgement is made.

For certain sections, physicists and X-ray engineers have been called upon to give their assistance in those parts where the medical man is no longer on his own ground.

May this work fulfil the aim of providing a textbook for all radiographers and all those who are interested in medical radiology. 


\section{PREFACE TO THE SECOND EDITION}

Medical radiology is an ever-expanding field of science and since the publication of the first edition, further developments and techniques have enabled me to add to the contents of this book. In the interest of greater clarity some things have been omitted, which in the light of new knowledge, might have proved a little confusing to the student.

In addition to this English edition, Spanish, French and German versions are in print.

I would like to express my thanks to those whose interest in this book has made these additional editions necessary.

The translation of a technical book is always a matter of some difficulty and I am grateful to those who have indicated points upon which misunderstanding could have been possible. I hope that these have been dealt with satisfactorily in this new edition.

Included in the appendix are references to some new advances, especially important being the introduction of television techniques into the field of medical radiology.

September 1960

The AUthor

\section{PREFACE TO THE THIRD EDITION}

For more than nine years the second edition has been able to meet the requirements made of it, even though here and there the need for corrections and supplements was becoming more and more urgent. A thoroughgoing overhaul of the contents had to be performed. This was especially necessary for the diagnostic part. At one time I considered splitting the book up into two distinct parts: one diagnostic, the other therapeutic. But, as a broad common base already existed and as there are still many countries where the radiologist practices diagnostics as well as radiotherapy - albeit perhaps not with the most advanced modern refinements - I dropped the idea, and so the book is presented in its previous form. I have received valuable suggestions and have tried to incorporate them in the text and figures.

I wish here to express my gratitude to Mrs. B. King-Linton and Miss A. Monhemius, both qualified radiographers, for checking the technical terminology for accuracy on the one hand and for the execution of the corrections and the new drawings on the other.

I sincerely hope that this book will contribute to standardizing the level of the educational syllabus for radiographers and radiological technicians in many countries. 


\section{CONTENTS}

PREFACE ........................ .

INTRODUCTION ...................... 1

\section{Chapter I SOME PHYSICAL CONCEPTS}

1.1 Definitions and units ................. . . 3

1.2 Direct current and alternating current . . . . . . . . . . . . . 5

1.3 Transformers and auto-transformers .............. 6

1.4 Electromagnetic spectrum . . . . . . . . . . . . . . . . . . . . . . 9

1.5 Origin and production of X-rays . . . . . . . . . . . . . . . 12

\section{Chapter II CONSTRUCTION AND OPERATING OF THE X-RAY TUBE}

2.1 Ion tubes . . . . . . . . . . . . . . . . . . . . . . . . . 13

2.2 Electron tubes. Hot cathode . . . . . . . . . . . . . . . . . . . . 14

2.3 Anode, target . . . . . . . . . . . . . . . . . . . . . . . . . . . 17

2.4 Effective focus . . . . . . . . . . . . . . . . . . . . . . . . . . . 19

2.5 Maximum permissible load on the focus, $\mathrm{kV}_{\mathrm{p}}$ and $\mathrm{kV}_{\mathrm{eff}}$. . . . . . . 20

2.6 Kinds of X-ray tube . . . . . . . . . . . . . . . . . . . . . . . 23

2.7 Further structural details; tube window, inherent filtration . . . . . . . . 28

2.8 Radiation hazard and radiation protection with "open" tubes . . . . . . . 29

2.9 Protection against high tension. Shock-proof apparatus . . . . . . . . . . 29

2.10 Air insulation. Cooling by air, cooling by water . . . . . . . . . . . . . 31

2.11 Oil insulation and oil cooling . . . . . . . . . . . . . . . . . . . . . 31

2.12 X-ray protection with insulated tubes . . . . . . . . . . . . . 35

2.13 Beam cross-section. . . . . . . . . . . . . . . . . . . . . . . . . . 37

2.14 Valves and semiconductor rectifiers . . . . . . . . . . . . . . 38

2.15 Summary . . . . . . . . . . . . . . . . . . . . 42

\section{Chapter III PROPERTIES OF X-RAYS}

3.1 The X-ray spectrum . . . . . . . . . . . . . . . . . . . . 44

3.2 Main properties of X-rays . . . . . . . . . . . . . . . . . . . . . . . 46

3.3 Penetrating power . . . . . . . . . . . . . . . . . . . . . . . 46

3.3.1 Effect on matter . . . . . . . . . . . . . . . . . . . . 46

3.3.2 The quality of X-radiation . . . . . . . . . . . . . . . . . 54

3.3.3 Half Value Thickness (H.V.T.) . . . . . . . . . . . . . . . . 55

3.3.4 Composition of the emergent beam . . . . . . . . . . . . . . . . 59

3.4 Luminescent effect . . . . . . . . . . . . . . . . . . . . . . . . . . 60

3.5 The photographic effect of X-rays . . . . . . . . . . . . . . . . 61

3.5.1 Photographic action of light rays and X-rays . . . . . . . . . . . 61

3.5.2 Intensifying screens . . . . . . . . . . . . . . . . 64

3.6 The ionizing power of X-rays . . . . . . . . . . . . . . . . . 64

3.6.1 The definition of ionization . . . . . . . . . . . . . . . . . 64

3.6.2 The R-unit . . . . . . . . . . . . . . . . . . . . . . . 66

3.6.3 The $\mathrm{R}$ and the rad . . . . . . . . . . . . . . . . . 68

3.7 The biological effect of X-rays . . . . . . . . . . . . . . . . . . . . 69

3.7.1 Effect on living tissue. . . . . . . . . . . . . . . . . . . . . . . 69

3.7.2 Genetic effect . . . . . . . . . . . . . . . . . . 70 


\section{Chapter IV METHODS OF IMAGE FORMATION AND LAWS OF PROJECTION}

4.1 Formation of the visible radiation image. . . . . . . . . . . . . . . 72

4.2 Making the radiation image visible . . . . . . . . . . . . . . 73

4.3 Quality of the visible image . . . . . . . . . . . . . . . . . 75

4.4 Inverse square law . . . . . . . . . . . . . . . . . . . . 76

4.5 Superimposition . . . . . . . . . . . . . . . . . . . . 77

4.6 Parallax and the "end on" effect . . . . . . . . . . . . . . . . . . 77

4.7 Magnification and distortion . . . . . . . . . . . . . . . . . 81

4.8 Orthodiagraphy and orthodiametry . . . . . . . . . . . . . . . . 82

4.9 Teleradiography . . . . . . . . . . . . . . . . . . . . . . . 83

4.10 Contact radiography . . . . . . . . . . . . . . . . 85

4.11 Directions of projection . . . . . . . . . . . . . . . . . . 86

4.12 Standardized projections and spotfilm technique (enlargement) . . . . . . . 87

4.13 Stereoradiography . . . . . . . . . . . . . . . . . . . . . . 88

4.14 Viewing of stereo images . . . . . . . . . . . . . . . . . . . . 91

4.15 Stereofluoroscopy . . . . . . . . . . . . . . . . . . . . . 94

4.16 Body-section radiography. Tomography . . . . . . . . . . . . . . . 95

4.17 Simultaneous multisection radiography . . . . . . . . . . . . . . 100

4.18 Transversal tomography . . . . . . . . . . . . . . . . . 101

4.19 Pantomography . . . . . . . . . . . . . . . . . . . . 103

4.20 Panoramic radiography, panorama exposures . . . . . . . . . . . . . 104

4.21 Radiological magnification (enlargement) technique . . . . . . . . . 105

4.22 Photo fluorography . . . . . . . . . . . . . . . . . . 108

4.23 Kymography . . . . . . . . . . . . . . . . . . . . . . . . . 112

4.24 Xeroradiography . . . . . . . . . . . . . . . . . . . . 114

4.25 Polaroid radiography . . . . . . . . . . . . . . . . . 114

4.26 Scannography . . . . . . . . . . . . . . . . . . . . . 115

4.27 Autoradiography . . . . . . . . . . . . . . . . . . . . . . . . 115

4.28 Micro-radiography . . . . . . . . . . . . . . . . . 116

4.29 X-ray microscopy. . . . . . . . . . . . . . . . . . . . . 116

\section{Chapter V IMAGE INTENSIFICATION AND X-RAY TELEVISION}

5.1 Luminance and the role of the human eye in fluoroscopy . . . . . . . 117

5.2 The electronic image intensifier . . . . . . . . . . . . . . . . 118

5.3 Definition, contrast and noise in image intensification . . . . . . . . . 121

5.4 Light intensification . . . . . . . . . . . . . . . . 124

5.5 Methods of observing the output screen . . . . . . . . . . . . . 125

5.6 Television cameras . . . . . . . . . . . . . . . . 126

5.7 Quantum noise and electrical noise . . . . . . . . . . . . . . . . . 129

5.8 X-ray television fluoroscopy . . . . . . . . . . . . . . . . . . 129

5.9 The perceptibility of detail . . . . . . . . . . . . . . . . . 131

5.10 The size of object that can be reproduced . . . . . . . . . . . . . . . 132

5.11 Improved observation by influencing the brightness . . . . . . . . . . . . 132

5.12 Stabilization of the luminance of the I.I. output screen . . . . . . . . . . 133

5.13 Stabilization of the brightness of the TV monitor screen . . . . . . . . . . 134

5.14 Combined stabilization of the luminance of the I.I and of the TV monitor screen 135

5.15 Sharpness of the TV image . . . . . . . . . . . . . . 136

5.16 Enlargement in the intensified fluoroscopy . . . . . . . . . . . . . . . 137

5.17 Reproduction of the output screen by photographic methods . . . . . . 138

5.18 Single-shot technique . . . . . . . . . . . . . . . . . . 139

5.19 Rapid series technique . . . . . . . . . . . . . . . . . 139 
5.20 Cinefluorography . . . . . . . . . . . . . . . . . . 140

5.21 Density control and stabilization . . . . . . . . . . . . . . . 141

5.22 Size and grade of cinefluorographic films . . . . . . . . . . . . . . . . 142

5.23 Fluorography from the TV monitor image. . . . . . . . . . . . . . . . 144

5.24 Video recording systems . . . . . . . . . . . . . . . . . . . . 145

5.25 Instrumentation associated with intensified fluoroscopy, fluorography and cinefluorography ... . . . . . . . . . . . . . 146

5.26 Possibilities offered by the image intensifying and television systems. Remote control .................... . . 147

\section{Chapter VI PERCEPTIBILITY OF DETAIL IN THE X-RAY IMAGE}

6.1 Intrinsic unsharpness . . . . . . . . . . . . . . . . . . . . 151

6.2 Objective and subjective contrast . . . . . . . . . . . . . . 151

6.3 Quality of the detail . . . . . . . . . . . . . . . 152

6.3.1 Size of the detail . . . . . . . . . . . . . . 152

6.3.2 Degree of detail contrast . . . . . . . . . . . . . . . 153

6.3.3 Degree of unsharpness or size of the contrast transition zone . . . . . 154

6.3.4 The brightness of the detail . . . . . . . . . . . . . 155

6.4 The degree of adaptation of the eye . . . . . . . . . . . 156

6.5 The visual power of the eye . . . . . . . . . . . . . . . . 157

6.6 The modulation transfer function . . . . . . . . . . . 158

\section{Chapter VII DEFINITION (SHARPNESS)}

7.1 Definition . . . . . . . . . . . . . . . . . . 163

7.2 Geometric unsharpness $\left(U_{g}\right) \ldots \ldots$. . . . . . . . . . . . 163

7.3 Movement unsharpness $\left(U_{m}\right) \ldots \ldots$. . . . . . . . . . . . . . . . 167

7.4 Unsharpness caused by intensifying screens $\left(U_{t}\right) \ldots \ldots$. . . . . . . . . . . 169

7.5 Unsharpness caused by the cassette . . . . . . . . . . . . . . . . . . 170

7.6 Film unsharpness . . . . . . . . . . . . . . . . . . . . . 170

7.7 Law of uniformity . . . . . . . . . . . . . . . . . . . 171

7.8 Examples . . . . . . . . . . . . . . . . . . . . . 171

7.9 Intrinsic unsharpness of fluorescent screens . . . . . . . . . . . . 172

\section{Chapter VIII CONTRAST}

8.1 The radiation contrast. . . . . . . . . . . . . . . . . . 173

8.2 The adverse effect of scattered radiation upon contrast . . . . . . . . 175

8.3 Methods of overcoming scattered radiation . . . . . . . . . . . . . 176

8.4 The influence of film, intensifying screen and fluorescent screen upon image contrast . . . . . . . . . . . . . . . . . 185

8.5 Contrast media . . . . . . . . . . . . . . . . . . . . . . . 186

8.6 Summary of the means of increasing contrast in radiography and fluoroscopy 187

Chapter IX QUALITIES OF FLUOROSCOPIC SCREENS, RADIOGRAPHIC FILMS AND INTENSIFYING SCREENS

9.1 The luminous efficiency of the fluoroscopic screen . . . . . . . . . . . . 189

9.2 Structure of the fluorescent screen . . . . . . . . . . . . . . . . . 191

9.3 Fluoroscopy . . . . . . . . . . . . . . . . . . . . . . . . . . . . . 191

9.4 The fluorescent screen of the image intensifier; fluoroscopy with image intensifier . . . . . . . . . . . . . . . . . . . 192

9.5 Structure of X-ray film . . . . . . . . . . . . . . . 193 
9.6 Photographic density . . . . . . . . . . . . . . . . . . . . . 195

9.7 Base density . . . . . . . . . . . . . . . . . . . . . . . . . . . 196

9.8 Fog density . . . . . . . . . . . . . . . . . . . . . . . . . . 196

9.9 The characteristic curve . . . . . . . . . . . . . . . . . . . . . . . . 197

9.10 The gradation of the film . . . . . . . . . . . . . . . . . . . . 199

9.11 Film sensitivity . . . . . . . . . . . . . . . . . . . 202

9.12 Film quality . . . . . . . . . . . . . . . . . . . . . . . . 202

9.13 Density range, exposure range and object contrast range . . . . . . . . 203

9.14 No-screen film . . . . . . . . . . . . . . . . . . . . . . . 205

9.15 Intensification factor . . . . . . . . . . . . . . . . 206

9.16 Combination screens . . . . . . . . . . . . . . . . . . . . . 206

9.17 Gradation of the film/screen combination . . . . . . . . . . . . . . . . 208

9.18 Detail perceptibility when using intensifying screens . . . . . . . . . . . 208

9.19 Unit density dose . . . . . . . . . . . . . . . . . . . . . . . . . . 209

9.20 Comparison between intensifying screen and fluoroscopic screen . . . . . . 210

9.21 Cassettes . . . . . . . . . . . . . . . . . . . . . . 211

9.22 A few words about "X-ray paper" . . . . . . . . . . . . . . 212

\section{Chapter X PROCESSING TECHNIQUE}

10.1 Introduction . . . . . . . . . . . . . . . . . . . . 213

10.2 Installation of the processing room . . . . . . . . . . . . . . 214

10.3 The dry side . . . . . . . . . . . . . . . . . . . . 221

10.4 The wet side. . . . . . . . . . . . . . . . . . . . . . . 222

10.5 Developing . . . . . . . . . . . . . . . . . . . . 225

10.6 Rinsing, stop bath . . . . . . . . . . . . . . . . . . . . . . 229

10.7 Fixing. . . . . . . . . . . . . . . . . . . . . 230

10.8 Washing. . . . . . . . . . . . . . . . . . . . . 232

10.9 Drying . . . . . . . . . . . . . . . . . . . . . . . . . 233

10.10 Processing room procedure . . . . . . . . . . . . . . . . . . . 234

10.11 Automation of film processing, processing machines. . . . . . . . . . . 238

10.12 Special processing procedures for manual operation . . . . . . . . . . . 241

10.13 Unsatisfactory photographic results . . . . . . . . . . . . . . . . . . . 243

10.14 Other photographic work . . . . . . . . . . . . . . . . 246

\section{Chapter XI FACTORS RELATING TO THE EXPOSURE OF THE FILM}

11.1 Electrical factors . . . . . . . . . . . . . . . . . 256

11.2 Correction of exposure data . . . . . . . . . . . . . . . . . 257

11.3 Relation between kilovoltage and mAs product . . . . . . . . . . . . . 259

11.4 Correction for body thickness . . . . . . . . . . . . . . . . . . . . . 263

11.5 The influence of film and apparatus . . . . . . . . . . . 265

\section{Chapter XII COMPOSITION OF EXPOSURE TABLES}

12.1 Basic exposure tables . . . . . . . . . . . . . . . . . . . . . . 268

12.2 Test exposures . . . . . . . . . . . . . . . . . . . 270

12.3 Basic exposure charts . . . . . . . . . . . . . . . . . 272

\section{Chapter XIII SPECIAL EXPOSURE TECHNIQUES}

13.1 The automatic density control . . . . . . . . . . . . . . . . . . 293

13.2 Optimum results by automatic exposure control . . . . . . . . . . . 296 
13.3 Optimum loading by means of falling load. . . . . . . . . . . . . . . . 298

13.4 Brightness stabilization and density stabilization . . . . . . . . . . . . . 300

13.5 Exposure techniques at higher tensions . . . . . . . . . . . . . . . . . 301

13.6 Applications of high-tension exposure technique . . . . . . . . . . . . 303

13.7 Application of low tensions . . . . . . . . . . . . . . . . . . . . . . 304

13.8 Pulse technique. . . . . . . . . . . . . . . . . . . . . . . 305

\section{Chapter XIV RADIOGRAPHIC TECHNIQUE IN GENERAL}

14.1 Radiographic projections . . . . . . . . . . . . . . . . . . . . 307

14.2 Position of the cassette . . . . . . . . . . . . . . . . . . . . . . . 308

14.3 Right and left markers . . . . . . . . . . . . . . . . . . . . 309

14.4 Limiting the beam . . . . . . . . . . . . . . . . . . . . . . . 311

14.5 Avoidance of superimposition . . . . . . . . . . . . . . . . . . . . 313

14.6 Compression. . . . . . . . . . . . . . . . . . . . 315

14.7 Immobilization. . . . . . . . . . . . . . . . . . . . 315

14.8 Bucky radiographs . . . . . . . . . . . . . . . . . . . 316

14.9 Film sizes . . . . . . . . . . . . . . . . . . . . . . . . . . . . . 316

14.10 Manners of X-ray workers in dealing with patients . . . . . . . . 317

\section{Chapter XV SPECIAL RADIOGRAPHIC TECHNIQUES}

15.1 Introduction. . . . . . . . . . . . . . . . . . . . . . 319

15.2 Stereoscopic radiographs . . . . . . . . . . . . . . . . . . . . 319

15.3 Tomographs . . . . . . . . . . . . . . . . . . . 321

15.4 Radiological magnification. . . . . . . . . . . . . . . . 323

15.5 Vasography or angiography . . . . . . . . . . . . . . . . . 324

15.6 Bronchography, myelography, etc. . . . . . . . . . . . . . 325

15.7 Photo fluorography . . . . . . . . . . . . . . . . . . . . . 326

15.8 Radiography in combination with the image intensifier . . . . . . . . . 327

15.9 Contrast media. . . . . . . . . . . . . . . . . . . . . . 327

15.10 Mammography. . . . . . . . . . . . . . . . . . . . 332

15.11 Geometric methods . . . . . . . . . . . . . . . . . . . . . . . 333

15.12 Radiography during hip-nailing . . . . . . . . . . . . . . . . 334

15.13 Pelvimetry. . . . . . . . . . . . . . . . . . . 335

15.14 Large size radiography . . . . . . . . . . . . . . . . 335

15.15 Reduction of fractures . . . . . . . . . . . . . . . . . . 336

15.16 Dental radiography . . . . . . . . . . . . . . . . 336

\section{Chapter XVI APPARATUS FOR X-RAY DIAGNOSIS}

16.1 High-tension (H.T.) cables. . . . . . . . . . . . . . . . . 338

16.2 Half-wave apparatus . . . . . . . . . . . . . . . . . . . . 338

16.3 One-valve and two-valve H.T. generators . . . . . . . . . . . . . . 341

16.4 Four-valve H.T. generators . . . . . . . . . . . . . . . . . . . . 342

16.5 Six-valve H.T. generators . . . . . . . . . . . . . . . . . . . . . . 344

16.6 Condenser-discharge apparatus . . . . . . . . . . . . . . . 346

16.7 The importance of mains voltage correction . . . . . . . . . . . . . 346

16.8 Classification of apparatus. . . . . . . . . . . . . . . . . . . 347

16.9 Choice of tube . . . . . . . . . . . . . . . . . . . . . . . . 349

16.10 Operation of the apparatus . . . . . . . . . . . . . . 350

16.11 Control desks . . . . . . . . . . . . . . . . . . . . . 353

16.12 Remote control "télécommande" . . . . . . . . . . . . . . . . . . 359

16.13 Diagnostic dosemeters. . . . . . . . . . . . . . . . . . . 360 


\section{Chapter XVII DIAGNOSTIC STANDS AND ACCESSORIES}

17.1 Simple stands for radiography . . . . . . . . . . . . . . . 362

17.2 Stands for fluoroscopy . . . . . . . . . . . . . . . 363

17.3 Serial changers, spot-film exposures . . . . . . . . . . . 366

17.4 Bucky tables. . . . . . . . . . . . . . . . . . . 368

17.5 Universal stands . . . . . . . . . . . . . . . . . . . . . . . . 371

17.6 Tomographs and tomographic attachments . . . . . . . . . . 372

17.7 Special stands . . . . . . . . . . . . . . . . . . . . 373

\section{Chapter XVIII THE BIOLOGICAL EFFECT OF RADIATION AND METHODS OF IRRADIATION}

18.1 Nature of the biological effect of radiation . . . . . . . . . . . . 378

18.2 Morphological and physiological reactions. Latent period . . . . . . . . . 379

18.3 Differences in radiosensitivity . . . . . . . . . . . . . . . . . . . 381

18.4 Factors that influence radiosensitivity . . . . . . . . . . . . . 383

18.5 The irradiation of benign and malignant diseases . . . . . . . . . . . 385

18.6 Elective effect, time factor, fractionation, protraction . . . . . . . . . . . 387

18.7 Influence of the quality of the radiation, rad, R.B.E., rem . . . . . . . . . 391

18.8 Influence of the irradiated volume, volume factor . . . . . . . . . . . . . 393

18.9 Reaction of the skin to irradiation in single dose . . . . . . . . . . . . . 394

18.10 Reaction of the skin to irradiation in fractionated dose . . . . . . . . . 395

18.11 Skin reaction in different forms of irradiation . . . . . . . . . . . . . 396

18.12 Curative and palliative effect . . . . . . . . . . . . . . . . . . . 398

18.13 Other methods of treating malignant growths and systemic diseases . . . . . 400

\section{Chapter XIX DOSIMETRY}

19.1 Methods of measuring dose . . . . . . . . . . . . . . . . . . . . . 402

19.2 Air-equivalent tissues and tissues with no air-equivalence . . . . . . . . . 404

19.3 Dosemeters . . . . . . . . . . . . . . . . . . . . . . . . . 406

19.4 Standard ionization chambers . . . . . . . . . . . . . . 407

19.5 Thimble ionization chambers. . . . . . . . . . . . . . . . . . . . . 407

19.6 Condenser chambers . . . . . . . . . . . . . . . . . . . . . . . 411

19.7 Charge and discharge in dosemeters. . . . . . . . . . . . . . . . . . 412

19.8 Check of function of dosemeters . . . . . . . . . . . . . . . . . . . . 413

19.9 Direct and indirect methods of measurement . . . . . . . . . . . . . 414

19.10 Dose rate indicator . . . . . . . . . . . . . . . . . . . . . 415

19.11 Clockwork dosemeter . . . . . . . . . . . . . . . . . . . . . . . 416

19.12 Precautions in measurement . . . . . . . . . . . . . . . . . 417

\section{Chapter XX THE DOSAGE OF X-RAYS}

20.1 Depth-dose curves . . . . . . . . . . . . . . . . . . . . . 419

20.2 Quality of the rays. Half-value thickness. . . . . . . . . . . . 420

20.3 Focus-skin distance . . . . . . . . . . . . . . . . . . . . 423

20.4 The size of the irradiated field. Scattered radiation . . . . . . . . . . . . 424

20.5 Nature of the tissue. . . . . . . . . . . . . . . . . . . . . . . 427

20.6 Quantity, exposure, exposure rate. . . . . . . . . . . . . . . . . . 427

20.7 "Röntgen value" and calculation of dosage in the body . . . . . . . . . . . 430

20.8 Dosage tables for stationary radiation. . . . . . . . . . . . . . . . 432

20.9 Use of dosage data for irradiation tables. . . . . . . . . . . . . . 442 
20.10 Isodose surfaces . . . . . . . . . . . . . . . . . . . . 443

20.11 Volume dose; integral absorbed dose . . . . . . . . . . . . . . . 446

20.12 Half value thickness in tissue. Depth quotient . . . . . . . . . . . 449

\section{Chapter XXI SUPERFICIAL THERAPY}

21.1 Quality of radiation in superficial therapy . . . . . . . . . . . 452

21.2 Grenz rays. . . . . . . . . . . . . . . . . . . . . 452

21.3 Soft rays . . . . . . . . . . . . . . . . . . 455

21.4 Moderately hard rays . . . . . . . . . . . . . . . 455

21.5 Width of the beam . . . . . . . . . . . . . . . . 456

21.6 The irradiation of large fields . . . . . . . . . . . . . . . . . . 457

21.7 The irradiation of eczema, inflammations, etc. . . . . . . . . . . . . 458

21.8 Epilation . . . . . . . . . . . . . . . . . . . . . 459

21.9 The irradiation of skin tumours . . . . . . . . . . . . . . . 462

21.10 Accessories for superficial therapy . . . . . . . . . . . . . . . . 462

21.11 Apparatus for superficial therapy . . . . . . . . . . . . . . . 463

\section{Chapter XXII DEEP THERAPY}

22.1 Deep therapy and medium therapy . . . . . . . . . . . . . 465

22.2 Tumour dose . . . . . . . . . . . . . . . . . . . . 465

22.3 Methods of increasing the depth dose . . . . . . . . . . . . . . . 467

22.4 Dose distribution in moving-field therapy . . . . . . . . . . . . . 479

22.5 Dose determination in moving-field therapy . . . . . . . . . . . . 485

22.6 Apparatus for conventional deep therapy . . . . . . . . . . . . . 488

22.7 Greinacher circuit . . . . . . . . . . . . . . . . . . . 489

22.8 Villard circuit . . . . . . . . . . . . . . . . . . 490

22.9 The control desk, automation . . . . . . . . . . . . . . . . . . 491

22.10 Accessories . . . . . . . . . . . . . . . . . . . 494

\section{Chapter XXIII SUPERVOLTAGE THERAPY}

23.1 Megavolt therapy. . . . . . . . . . . . . . . . . . . 501

23.2 Apparatus for megavolt therapy . . . . . . . . . . . . . . . . 503

23.3 The Van de Graaff generator . . . . . . . . . . . . . . . . . . 503

23.4 The linear accelerator . . . . . . . . . . . . . . . . . . . . . . 504

23.5 The betatron. . . . . . . . . . . . . . . . . . . . 505

23.6 Electron beams. . . . . . . . . . . . . . . . . . . 506

23.7 Other corpuscular radiation . . . . . . . . . . . . . . . . . . 508

23.8 Hard gamma radiation and megavolt radiation. . . . . . . . . . . . . . 509

23.9 The cobalt bomb. . . . . . . . . . . . . . . . . . . . . . . . 510

23.10 The caesium source. . . . . . . . . . . . . . . . . . . . . . . 511

23.11 Cobalt and caesium therapy equipment . . . . . . . . . . . . . . 512

23.12 Comparison between megavolt equipment and cobalt equipment . . . . . . 514

23.13 Accessories for supervoltage therapy . . . . . . . . . . . . . . . . 516

\section{Chapter XXIV CONTACT THERAPY}

24.1 Nature of contact therapy . . . . . . . . . . . . . . . . . 520

24.2 Methods of Chaoul and Van der Plaats . . . . . . . . . . . . . 521

24.3 The applications of contact therapy. . . . . . . . . . . . . . . 528

24.4 Choice of portal, homogenization factor. . . . . . . . . . . . . . . . 529 
24.5 The dosage . . . . . . . . . . . . . . . . . . . . . . . . 531

24.6 Radiation protection and automation . . . . . . . . . . . . . 532

24.7 Comparison of contact therapy with deep therapy . . . . . . . . . 534

\section{Chapter XXV THERAPY WITH RADIOACTIVE ELEMENTS}

25.1 Historical survey . . . . . . . . . . . . . . . . . . 536

25.2 Basic concepts of nuclear physics; isotopes. . . . . . . . . . . . 537

25.3 Symbols. . . . . . . . . . . . . . . . . . . . . 541

25.4 Natural radioactivity; transmutation of the elements . . . . . . . . . . 542

25.5 Curie therapy . . . . . . . . . . . . . . . . . . . . 544

25.6 Artificial radioactivity . . . . . . . . . . . . . . . . . . . 546

25.7 Radioactive elements in curie therapy . . . . . . . . . . . . . . . . . . 548

25.8 Irradiation techniques. . . . . . . . . . . . . . . . . . . . . . . . 548

25.9 Units of dosage in curie therapy . . . . . . . . . . . . . . . . 550

25.10 Dosage in curie therapy . . . . . . . . . . . . . . . . . . . . . 551

25.11 Dose determination in curie therapy . . . . . . . . . . . . . . 553

25.12 The detection of radioactivity; counters . . . . . . . . . . . . . . 553

25.13 Therapeutic applications of radioactive elements . . . . . . . . . . . . 555

25.14 Curie therapy versus therapy with electrical equipment . . . . . . . . . . 559

25.15 Radioactive tracing. . . . . . . . . . . . . . . . . . . 560

Chapter XXVI RADIATION HAZARD AND PROTECTIVE MEASURES IN DIAGNOSTICS AND THERAPY

26.1 Natural and other radiations. . . . . . . . . . . . . . . . . 563

26.2 The radiation hazard . . . . . . . . . . . . . . . . . . . . 564

26.3 Permissible dose . . . . . . . . . . . . . . . . . . . . . . . . . . . 566

26.4 Protection of X-ray personnel . . . . . . . . . . . . . . . . . . . . . 568

26.5 Protection of the patient. . . . . . . . . . . . . . . . . . . . . . . 570

26.6 Supervision of protective measures . . . . . . . . . . . . . . . . . 573

26.7 The importance of some modern constructions in therapy apparatus . . . . 576

26.8 Conclusion . . . . . . . . . . . . . . . . . . . . . . 577

Index ......................... 579 